\title{
WALTER BENJAMIN À BRASILEIRA? A EXTREMA-DIREITA BOLSONARISTA SOB A LUZ DOS CONCEITOS DE HISTORIOGRAFIA BURGUESA E ESTETIZAÇÃO DA POLÍTICA
}

Felipe Vieira Britto'

RESUMO: A partir de um resgate crítico das categorias de estetização da política e historiografia burguesa, apresentadas por Walter Benjamin respectivamente no ensaio "A obra de arte na era de sua reprodutibilidade técnica" e nas teses "Sobre o conceito de história", o trabalho tem como objetivo fazer uma análise da narrativa hegemônica, difundida no Brasil pelos meios privados de comunicação de massa, que levou à ascensão da extrema-direita representada na figura de Jair Bolsonaro. Tendo analisado, sob a lente de uma combinação entre as categorias benjaminianas e estudos de outros autores, o período iniciado em 2005, com o escândalo do "Mensalão" é encerrado em 2018, com a eleição de Jair Bolsonaro, o presente trabalho conclui que a ascensão da extremadireita no Brasil deve-se, em partes, a um processo de estetização da política característico da metodologia fascista.

PALAVRAS-CHAVE: Benjamin; Bolsonaro; estética; política; fascismo.

\section{WALTER BENJAMIN, BRAZILIAN WAY? THE BOLSONARIST FAR-RIGHT UNDER THE LIGHT OF THE CONCEPTS "BOURGEOIS HISTORIOGRAPHY" AND "AESTHETICIZATION OF POLITICS"}

Graduando em Filosofia (Licenciatura) pela Universidade Federal Fluminense.
ABSTRACT: Starting from a critical rescue of the concepts "aestheticization of politics" and "bourgeois historiography", presented by Walter Benjamin respectively in the essay "The work of art in the age of mechanical reproduction" and in the theses "On the philosophy of history", this paper has the objective of analyzing the hegemonic narrative, widespread in Brazil by the private mass media, that led to the rise of a far-right movement represented in the figure of Jair Bolsonaro. After analyzing the time period initiated in 2005 by the "Mensalão" scandal and ended in 2018 by the election of Jair Bolsonaro, with the lens of a combination between Walter Benjamin's concepts and studies by other authors, this paper concludes that the rise of the Brazilian far-right is due, partially, to a process of aestheticization of politics proper of the fascist methodology.

KEY-WORDS: Benjamin; Bolsonaro; aesthetics; politics; fascism. 


\section{INTRODUÇÃOO}

A relação que os campos da política e da estética guardam entre si é conhecida e estudada desde a Grécia Antiga. Platão (1996: 377a), a exemplo disso, expõe no Livro II d'A República sua preocupação com o impacto das obras de arte na configuração pedagógica e política da cidade ao expulsar dela os artistas. ${ }^{2}$ Em um ensaio sobre o conceito moderno de liberdade artística, Lukács (2010: 269) argumenta que "na Antiguidade, na Idade Média, e mesmo durante o Renascimento, a arte antiga fazia parte da vida pública e os artistas extraíam, sem hesitação, todas as consequências que este fato acarretava", o que para o autor inclui o entendimento de que "os artistas eram guiados em sua ideologia, em seus temas, na forma de sua expressão, pela sociedade onde a criação deles entrava como parte da vida pública". ${ }^{3}$

No entanto, há um problema fundamental percebido por Walter Benjamin no célebre ensaio acerca da reprodutibilidade técnica da arte: a obra de arte na Antiguidade guardava em si uma aura ${ }^{4}$ ritualística, que se devia à valorização de sua originalidade e autenticidade, propriedades esvaídas com o desenvolvimento das técnicas de reprodução em massa. Essa aura sumiu e se esvaiu junto dela o valor de culto atrelado às suas propriedades auráticas, dando lugar a um valor de exposição. Benjamin descreve o valor de culto e o valor de exposição como "diametralmente opostos", e imputa em cada um desses valores um grau diretamente relacionado de reprodutibilidade técnica. Em outras palavras: quanto mais reproduzida uma obra é, menos valor de culto e mais valor de exposição ela tem (e vice-versa).

Disso se desdobra uma oposição dialética entre os tipos de obra de arte que esta (se podemos chamar dessa forma, para relembrar a tradição marxista de Benjamin) "teoria do valor estético" compreende: com o desenvolvimento das técnicas de reprodução em massa, sobretudo a xilogravura e a imprensa, a obra de arte sofreu modificações radicais em sua própria forma. Como o autor explica, "a obra de arte reproduzida torna-se, progressivamente, a reprodução de uma obra de arte destinada à reprodutibilidade" (Benjamin 2014: 49). Essa perturbação estrutural na forma da arte e, portanto, no seu tipo
2 Pouco antes de 377a, Sócrates introduz o debate acerca de uma utilidade pedagógica da arte e a possibilidade para uma instrumentalização política dessa na organização da cidade.

3 A primeira publicação do texto data de 1968, portanto, posterior à morte de Walter Benjamin em 1940, de forma que a citação no primeiro parágrafo não tem objetivo de insinuar que o argumento de Benjamin se aprofunda cronologicamente a partir da constatação de Lukács. O aprofundamento sugerido é lógico-teórico.

4 O autor disserta amplamente sobre o conceito de aura no ensaio, dando a entender que a aura de uma obra de arte está intimamente relacionada à sua capacidade única, como objeto original, de arrebatar e transportar em outro momento, essa capacidade é descrita como "a aparição única de uma distância, por mais próxima que esteja" (Benjamin 2014: 46). 
de valor estético, significa também uma mudança na maneira como o público interage com a arte. Se antes uma obra de arte dotada de valor de culto fazia parte de uma relação ritualística com o público, em que a efetivação desse valor se dava justamente pela pouca quantidade de indivíduos apreciando uma obra única, agora a obra de arte dotada de valor de exposição tem a efetivação desse valor na sua apreciação em massa. O cinema é a forma de arte mais característica desse deslocamento: a obra não apenas pode ser reproduzida, ela deve ser reproduzida e, mais ainda, a sua possibilidade de existência se fundamenta nas técnicas de reprodução - em especial na segunda técnica, descrita no capítulo VI do ensaio de Benjamin (2014: 51), que tem por síntese a ideia de "uma vez é nenhuma vez", em oposição ao "de uma vez por todas" da primeira técnica. Uma das muitas manifestações do "uma vez é nenhuma vez", a título de ilustração, é a gravação de várias tomadas para uma mesma cena, prática comum na produção de vários filmes e que demonstra um caráter de "teste" ou, nos termos de Benjamin, "jogo", específico da produção dessa forma de arte. Como arte de massas, ou seja, uma arte destinada à - e originada na possibilidade de - reprodução em massa, o cinema não só manifesta a conhecida aproximação entre estética e política, mas dá outros significados e possibilidades para essa aproximação. Uma dessas possibilidades é a estetização da política, que será discutida de maneira mais aprofundada posteriormente.

O presente trabalho parte dessa teoria estética para a pergunta: ainda é possível se utilizar dessas categorias hoje para analisar fenômenos políticos concretos? Walter Benjamin, como os outros pensadores da Escola de Frankfurt, lançou-se na tarefa de explicar, pela via de um aspecto cultural do capitalismo, o fenômeno do fascismo surgido na Europa durante a primeira metade do século $X X$, em um ambiente turbulento de crise no capitalismo. Em uma tentativa de resgate crítico das categorias benjaminianas, este trabalho observa e combina com elas alguns estudos contemporâneos sobre a construção da narrativa política hegemônica no Brasil entre os anos de 2005 e 2018, propondo um encontro entre a estética e a política para a leitura de um fenômeno com urgência de ser estudado: a ascensão da extrema-direita brasileira, representada na figura de Jair Bolsonaro. Não cabe a este trabalho discutir questões terminológicas a fim de 
classificar ou não o governo e o projeto de Jair Bolsonaro como fascistas ou neofascistas. Por outro lado, compreende-se a pertinência de uma análise desse teor ao menos a respeito dos métodos de que o projeto bolsonarista se utiliza para mobilizar as massas de trabalhadores brasileiros e manter uma relativa popularidade. A partir dessa análise será possível responder a pergunta fundamental que originou o presente trabalho, bem como creditar ou não a ascensão da extrema-direita brasileira a um processo de "estetização da política".

\section{HISTORIOGRAFIA BURGUESA, CORTEJO AOS VENCEDORES E A ESTÉTICA FASCISTA}

Nas teses "Sobre o conceito de história", especialmente na tese VII, Walter Benjamin (2005: 70) disserta acerca do que identifica como "historicismo", ou a tradição historiográfica burguesa, e indaga: "com quem, afinal, propriamente o historiador do Historicismo se identifica afetivamente? A resposta é, inegavelmente: com o vencedor". Mais adiante, afirma que essa identificação afetiva com o vencedor ocorre "sempre em proveito dos vencedores de turno". Benjamin está falando, o tempo inteiro, de uma disputa de narrativas, uma disputa entre dois modelos de história. Segundo o autor, "nunca há um documento da cultura que não seja, ao mesmo tempo, um documento da barbárie". Esse duplo caráter do que chama de "documento", que compreende em si uma unidade dialética de contrários entre cultura e barbárie, é precisamente o ponto em que se evidencia a disputa de narrativas.

Michel Löwy (2005: 74) explica a tarefa que Benjamin atribui à historiografia revolucionária ("escovar a história a contrapelo") também com um duplo sentido, que por um lado é histórico e se trata de "ir contra a corrente da versão oficial da história, opondo-lhe a tradição dos oprimidos", e por outro é político, ditando que "será necessário nadar contra a corrente. Deixada à própria sorte, ou acariciada no sentido do pelo, a história somente produzirá novas guerras, novas catástrofes, novas formas de barbárie e opressão".

A advertência dada por Benjamin com isso é bem clara: a reprodução da narrativa das classes dominantes não pode e nem vai resultar, nunca, na vitória das classes oprimidas - muito pelo contrário, o resultado é a vitória de um inimigo "que não tem cessado de vencer". É preciso que uma narrativa histórica dos próprios oprimidos seja 
produzida e, com ela, a possibilidade de instrumentalizar o passado politicamente como elemento revolucionário.

Tal articulação entre passado, pela via da história, e presente, pela via da política, não é por acaso destacada e parece fazer parte de uma questão que percorre toda a obra de Walter Benjamin. E não é essa mesma questão que permeia o diagnóstico do autor a respeito da relação entre a obra de arte e o público? O tipo de relação que a historiografia burguesa guarda com a vitória da classe dominante não é, justamente, o mesmo que a estetização da política guarda com o triunfo do fascismo? Vejamos o ensaio "A obra de arte na era de sua reprodutibilidade técnica" (Benjamin 2014: 66) mais de perto:

Ele [o ator] sabe que, enquanto se posta diante da aparelhagem, está, em última instância, a lidar com a massa. É essa massa que irá controlá-lo. E justamente ela não é visível, ainda não está dada enquanto ele executa a performance artística que ela irá controlar. A autoridade desse controle é elevada por essa invisibilidade. Certamente não pode ser esquecido que a aplicação política desse controle será postergada até que o filme tenha se libertado de sua exploração capitalista, pois os potenciais revolucionários desse controle são transformados em contrarrevolucionários pela indústria cinematográfica. O culto às estrelas por ela reivindicado conserva não apenas a magia da personalidade, que já há tempos consiste no brilho putrefato de seu caráter de mercadoria, mas também seu complemento, o culto do público, exige ao mesmo tempo um estado corrupto da massa, que o fascismo busca colocar no lugar de sua consciência de classe.

Duas importantes linhas de raciocínio podem ser inicialmente extraídas do trecho acima apresentado: a) o que o autor entende por "culto do público", precisamente como o ato de o público cultuar (as estrelas da indústria cinematográfica), deriva do caráter mercadológico do cinema submetido à lógica do capital e, portanto, pode ser entendido como uma deturpação da característica de massas do cinema; b) essa deturpação, ou corrupção, da característica de massas do cinema, por um lado, ocorre como deturpação do próprio comportamento do público e, por outro, substitui algo que no espaço desse comportamento deturpado deveria residir: a consciência de 
classe. Por fim, o "culto às estrelas" parece se tratar, como o "culto à beleza" (Benjamin 2014: 48), de um ainda mais novo refúgio para a aura, pois são de mesma natureza a fuga do valor de culto perdido com a reprodução em massa de fotografias para o rosto fotografado e a fuga do valor de culto extinto em uma forma de arte originada na reprodutibilidade técnica para o corpo do ator.

Da segunda noção, deve-se compreender que, por substituir a consciência de classe, o comportamento de culto do público que o cinema sob a lógica do capital promove só pode ser uma ferramenta utilizada dentro do escopo da luta de classes. Em outras palavras, as massas (as classes trabalhadoras) têm seu interesse de classe (a revolução) dissimulado em função dos interesses das classes dominantes (a contrarrevolução). É justamente nessa linha que opera o que, posteriormente no mesmo ensaio, Benjamin chama "estetização da política": o fascismo ${ }^{5}$ resolveu o problema do apoio popular permitindo que as massas trabalhadoras expressem suas reivindicações políticas sem, entretanto, concretizá-las. Esse é o "estado corrupto da massa" a que o autor se refere, rigorosamente, a sobreposição da estética por cima da política.

Paralelamente, da primeira noção o caminho lógico a ser seguido é: se é verdade que esse é um "estado corrupto" da característica de massas do cinema fabricado sob as medidas do capitalismo, qual é então seu estado legítimo? Uma das maneiras de responder essa pergunta é voltando à relação entre obra e público: assumir uma característica de massas que o cinema possui, e assumir que essa característica foi corrompida pelo capital para que um determinado comportamento substituísse a consciência de classe das massas é também assumir que, fora dessa lógica corruptiva, a característica de massas do cinema convive e se relaciona com a consciência de classe nas massas. Há, portanto, uma contradição dialética que se apresenta sob a aparência da disputa entre um cinema reacionário e um cinema revolucionário.

Podemos nos valer de uma interessante semelhança teórica e recorrer ao texto de Susan Buck-Morss (2009: 28), "A tela do cinema como prótese de percepção", para ampliar ainda mais o problema da relação entre obra e público:
5 Por ser amplamente utilizado, o termo "fascismo" por vezes se confunde e se esvazia de significado. O teórico da tradição marxista que mais aprofundou o estudo do fascismo como fenômeno surgido no interior de uma crise do capital foi Thalheimer (1975), em "Sobre o fascismo", texto que parte da profunda análise que Marx (2011) despende em "O 18 Brumário de Luís Bonaparte" como lente para compreender o fascismo dentro de um contexto de crise do capital e necessidade de reestruturação da ditadura da burguesia em uma forma mais radical. A característica fundamental do fascismo que interessa a este trabalho, entretanto, é aquela exposta por Robert Paxton (2007: 13-14) em "Anatomia do fascismo": "Embora Engels previsse que os inimigos da esquerda acabariam por lançar um contra-ataque, ele, em 1895, não poderia esperar que esse ataque viria a conquistar o apoio das massas. Uma ditadura antiesquerdista cercada de entusiasmo popular - essa foi a combinação que os fascistas conseguiram criar no curto espaço de uma geração". Se tentarmos entender o fenômeno sob a lente da ideologia, da qual Marx (2007: 47) tratou em "A ideologia alemã", uma das chaves de leitura pode ser a suposição de que o fascismo exacerba a capacidade das ideias da classe dominante de serem as ideias, de fato, dominantes. 
A coletividade do século $X X$, que constrói sua identidade na base da imagem ao invés da palavra, é, ao menos potencialmente, uma verdadeira comunidade internacional, como bem sabiam os produtores e distribuidores dos primeiros filmes mudos. Essa é a vantagem política do cinema como prótese de cognição. Mas se esta coletividade é de conformismo e não de consenso, se a uniformidade substitui a universalidade, abre-se a porta para a tirania. Se as 'verdades' são universais porque são experimentadas em comum mais que percebidas em comum porque são universais, então a prótese cinemática se torna um órgão de poder, e a cognição se torna doutrinamento. Quando a audiência de massa tem uma sensação de identidade imediata com a tela do cinema, e a própria percepcão se torna consenso, desaparece o espac,o para o debate crítico, intersubjetivo, e a discussão.

É na relação, ou mais rigorosamente, no espaço que essa relação pressupõe entre a obra e o público, que se manifesta a contradição. Há dois tipos de "coletividade" postos em dois lados diametralmente opostos por Buck-Morss: de conformismo e de consenso; a primeira originada de uma experiência comum, a segunda de uma percepção em comum. É identificando uma ou outra que se pode identificar qual tipo de universalidade coletiva de uma ou de outra deriva: conformada ou consentida. É também nessa mesma distinção que, em Benjamin, se origina o comportamento corrupto (compatível com o cinema reacionário) ou a consciência de classe (compatível com o cinema revolucionário) das massas.

Esse é o mesmo tipo de contradição que Walter Benjamin descreve nas teses "Sobre o conceito de história". Uma historiografia revolucionária, emergindo da tradição dos oprimidos, se contrapõe a uma historiografia reacionária. Em outro trecho do ensaio sobre a reprodutibilidade técnica, o autor também observa que "a maneira pela qual a percepção humana se organiza - o meio em que ocorre - não é apenas naturalmente, mas também historicamente determinada" (Benjamin 2014: 46). A pergunta de que partimos alguns parágrafos atrás foi se o tipo de relação que a historiografia burguesa guarda com a vitória da classe dominante não é o mesmo que a estetização da política guarda com o triunfo do fascismo. Mas o problema, ao que parece, se desdobra para além disso: e se, além do tipo de relação ser 
o mesmo, a estetização da política for uma forma historicamente determinada da historiografia burguesa se reproduzir? Essa hipótese, se verdadeira, significa que o triunfo do fascismo é também uma forma historicamente determinada de vitória da classe dominante.

\section{A REPRODUTIBILIDADE TÉCNICA: CINEMA E TELEVISÃO}

O estudo bibliográfico "História e tecnologias da televisão", de Abreu e Silva (2012: 2), traça uma linearidade dos avanços tecnológicos que possibilitaram o surgimento da televisão. Assim como o cinema, ela surge do desenvolvimento das técnicas de reprodução de imagem e som - desde a descoberta, por Jakob Berzellus em 1817, da possibilidade de transformação de energia luminosa em energia elétrica pelo selênio até o desenvolvimento dos aparelhos que possibilitaram a transmissão, em 1939, do discurso do presidente norte-americano Franklin D. Roosevelt na Feira de Amostras de Nova lorque, que marcou o início da comunicação eletrônica no continente americano. O surgimento da televisão, desse ponto de vista, pode ser lido como desdobramento do surgimento do cinema: o desenvolvimento das técnicas de reprodução que originaram o cinema avançou tanto que foi possível levar às telas para as casas das pessoas, certamente ampliando muito mais o alcance da reprodução em relação ao cinema. No Brasil, isso pode ser demonstrado, por exemplo, se considerados os dados do Censo 2010: ${ }^{6}$ De acordo com a pesquisa, 95,1\% das casas do país possuem pelo menos um aparelho de

6 Disponível em: https://censo2010.ibge. gov.br/. televisão.

Se a indústria cinematográfica, para Benjamin, consegue transformar em contra revolucionária a capacidade revolucionária do cinema para que nas massas se substitua a consciência de classe pelo comportamento corrompido de culto que atende ao interesse das classes dominantes, como isso se dá agora com a televisão? A indústria cinematográfica sob a lógica do capital serve aos interesses dos capitalistas, e isso certamente vale para a indústria televisiva como meio de comunicação de massas. No caso do Brasil, segundo o relatório publicado pelo Media Ownership Monitor ${ }^{7}$, cinco famílias controlam metade dos veículos de mídia com maior circulação, entre

7 Disponível em: https://brazil.momrsf.org/br/midia/tv/. 
pergunta que se pode fazer é: como é possível demonstrar a força com que a narrativa da historiografia burguesa se difunde nesse cenário? Se essa demonstração for possível, será possível também compreender o poder dessa forma histórica específica de estetização da política.

\section{A ESTETIZAÇÃO DA POLÍTICA: ANTES E AGORA}

A conhecida máxima de Joseph Goebbels, ministro da propaganda na Alemanha Nazista, de que "uma mentira dita muitas vezes se torna verdade", é uma síntese das vias pelas quais a estetização da política percorre. Ao operar no campo estético, a política manifesta uma característica específica, segundo Benjamin (2014: 83): "todos os esforços para estetizar a política culminam em um ponto. Esse ponto é a guerra". A razão disso para o autor é clara: as massas de trabalhadores que surgem com a proletarização crescente da humanidade, em função do desenvolvimento do capitalismo, tendem a pressionar pela mudança do regime de propriedade (revolução). O fascismo, entretanto, como ferramenta burguesa de manutenção do mesmo regime de propriedade, encontrou uma solução para esse problema: permitir que as massas reivindiquem suas necessidades políticas, mas não que elas as concretizem. Esse espaço que aparece entre a expressão e a concretização (da mudança do regime de propriedade) é onde a política encontra lugar para funcionar esteticamente, no sentido de confundir a expressão com concretização - uma confusão de natureza idêntica à exposta por Buck-Morss anteriormente: no lugar de uma universalidade consentida porque percebida coletivamente é assentada uma universalidade conformada porque experienciada coletivamente. Ou, nos termos de Walter Benjamin: sem a consciência de classe roubada das massas por uma política estetizada, outra consciência, compatível com um estado corrupto dessas massas, entra em ação.

O que ocorre, então, depois disso? Na seleção de ensaios escritos por Slavoj Žižek (2014: 238) e publicada sob o título "Violência", podemos encontrar um desdobramento: "As diferenças políticas diferenças condicionadas pela desigualdade política ou pela exploração econômica - são naturalizadas e neutralizadas em diferenças 'culturais', ou seja, em diferentes 'modos de vida' que são algo dado, 
inultrapassável". Trata-se de uma chave de leitura para o processo de estetização da política em Benjamin: dissimular problemas econômicos em problemas "culturais" é uma maneira eficaz de garantir a expressão política das massas e ao mesmo tempo negá-las a concretização dessas reivindicações.

\section{ANTES}

Através dessa chave de leitura pode ser compreendido o antissemitismo nazista. Em "A era dos extremos", o historiador Eric Hobsbawm (1995: 121-123) afirma que "o passado ao qual eles [os nazistas] apelavam era uma invenção" e "suas tradições, fabricadas". Sobre a propaganda antissemita, escreve: "os judeus estavam presentes em quase todo lugar e podiam simbolizar com facilidade tudo o que havia de mais odioso num mundo injusto" e "podiam servir como símbolos do odiado capitalista/financista".

Ao associar os judeus com os problemas sociais da Alemanha, o nazismo conseguiu fazer das massas o protagonista de um espetáculo estético, em que o herói - o soldado alemão - luta bravamente contra o inimigo - o judeu - e espera, ao fim dessa luta, a resolução dos problemas que, segundo a sua narrativa, esse inimigo trouxe. Tal mecanismo se apoia em duas premissas fabricadas: a) a de que todos esses problemas não existiam antes da chegada do inimigo, o que explica a obsessão com o passado glorioso; e b) a de que o inimigo incorpora, na forma de carne e osso, noções abstratas como "corrupção" e, portanto, sua eliminação física pode corrigir a realidade corrompida. Como a narrativa não encontra par na realidade, então o nazifascismo poderia eternamente recorrer à insuficiência da aplicação de suas próprias soluções para justificar a impossibilidade de retorno ao passado.

\section{DEPOIS}

Em 2005, a revista Veja publicou uma reportagem ${ }^{8}$ escancarando um suposto esquema de corrupção no interior do governo Lula (2003-2010), eleito pelo Partido dos Trabalhadores (PT). O partido foi criado como "de massas e não de vanguarda", como aponta Fábio Luís Barbosa dos Santos (2018: 89) no livro "Uma história da onda progressista sul-americana:1998-2016", organizando "o movimento sindical, os movimentos populares, as comunidades eclesiais de base e

8 A própria revista disponibilizou uma cronologia dos eventos: https://veja.abril.com. br/brasil/ossegredos-domensalao-dez-anosdepois/. 
a intelectualidade progressista brasileira", com o compromisso de modificar a realidade brasileira, marcada por uma radical desigualdade que contrasta com o progresso industrial e as riquezas naturais. $O$ escândalo estampado na revista Veja, no qual o governo federal era acusado de comprar votos parlamentares no Congresso Nacional, ficou conhecido como "Mensalão". O Jornal Nacional, carro-chefe da narrativa hegemônica no Brasil, passou a cobrir o desenvolvimento da história no cenário político brasileiro com entusiasmo. Segundo o estudo de Fábio Vasconcellos (2014: 113) intitulado "A construção de imagens do Jornal Nacional durante o escândalo do Mensalão",

O enquadramento de responsabilização, com seu forte caráter moral, teve maior predominância nas matérias sobre o "Mensalão" e, na maioria dos casos, sobre o PT, seus integrantes, aliados do governo e empresários foram apontados como tendo participação direta no caso.

Embora o autor deixe evidente que não foi rigorosamente possível encontrar uma relação de causalidade entre a cobertura midiática do caso e qualquer fenômeno político posterior (como eleições ou processos parlamentares), ele admite no mesmo estudo (Vasconcellos, 2014: 109) que:

\footnotetext{
A análise dos enquadramentos interpretativos do JN demonstra que houve uma disputa por compreensão do nível de responsabilidade de cada ator no esquema de corrupção, e o PT, nesse caso, foi visto como uma instituição moralmente reprovada, que abrigou um engenhoso plano de corrupção dentro do governo.
}

A justificativa para a apreensão da análise na deliberada estigmatização do PT por parte dos meios de comunicação de massa brasileiros pressupõe, nesse trabalho, uma oposição entre o interesse do partido, cuja base social são as massas de trabalhadores, e o interesse das classes dominantes brasileiras. Seja por um esvaziamento da "funcionalidade dos governos petistas do ponto de vista da ordem" (Santos, 2018: 89), ou por incompatibilidade radical de projetos, como alegam as lideranças petistas, o que é possível afirmar objetivamente sobre os conflitos de classe que motivaram a rejeição das classes dominantes ao projeto do PT é o esgotamento do "modo lulista de 
regulação do conflito social" (Santos, 2018: 89) em um momento de crise aguda do capitalismo que não mais comporta nenhuma convergência de interesses entre capital e trabalho.

Já em contexto de crise, outro episódio da política brasileira envolvendo o Partido dos Trabalhadores que marcou o imaginário popular foi a chamada "Operação Lava-Jato", uma investigação iniciada em 2014 que revelou um esquema de lavagem de dinheiro e propinas envolvendo contratos da Petrobras. Anita Hoffmann e Luís Mauro Sá Martino (2017: 148), afirmam que:

Os nomes da Operação Lava Jato, nesse sentido, embora
não revelem detalhes sobre os bastidores e procedimentos
propriamente jurídicos, estabelecem uma relação de
proximidade com o público acostumado com o ambiente
da mídia usando, em sua divulgação, elementos extraídos
desse universo os nomes de filmes e séries, por exemplo,
ou a utilização de uma ária de ópera repetidamente
divulgada na televisão.

O trabalho citado acima é uma interessante investigação sobre a utilização, por parte dos meios de comunicação, do modelo de "entretenimento" na cobertura da operação. Entre os exemplos citados pelos autores do estudo está a $24^{a}$ fase da investigação, momento em que o ex-presidente Lula foi conduzido coercitivamente - embora nunca tenha se negado a depor - por um contingente visivelmente exagerado ${ }^{9}$ de policiais federais fortemente armados. A fase recebeu o nome de "Aletheia". Embora exista espaço para um amplo debate sobre se o grande público conhece ou não o significado ${ }^{10}$ do termo, a Revista Época (de propriedade do Grupo Globo), na mesma semana, publicou uma matéria ${ }^{11}$ cujo único objetivo era explicar o termo para seus leitores, intitulada "O que significa Aletheia, o nome da $24^{a}$ fase da Operação Lava-Jato".

Ainda com o objetivo de compreender os impactos concretos da narrativa hegemônica dos meios de comunicação de massas na política brasileira, o Laboratório de Estudos de Mídia e Esfera Pública da UERJ desenvolveu uma ferramenta online batizada de Manchetômetro. ${ }^{12} \mathrm{Na}$ ferramenta, é possível inserir um termo (como "Lula", "PT", "Sérgio Moro" ou "Jair Bolsonaro"), e observar um gráfico
${ }^{9}$ O exagero nesse caso pode ser percebido principalmente na construção imagética do episódio pelos telejornais; a cena dos vários policiais armados batendo à porta do expresidente nas primeiras horas da manhã foi reproduzida incessantemente por dias.

10 Segundo Japiassú e Marcondes (2008: 94), "aletheia" é o termo do qual traduz-se "verdade" em Platão, como "desvelamento do ser", ou em Heidegger, como a "manifestação do ente". Também da mitologia grega o termo é conhecido por se tratar de uma manifestação espiritual da verdade.

11

Disponível em: https://epoca.globo.com /tempo/noticia/2016/03/ o-que-significa-aletheiao-nome-da-24-fase-dalava-jato.html. 
que se forma a partir da classificação de manchetes e chamadas dos principais jornais do Brasil (entre eles, o Jornal Nacional, da TV Globo). Pode-se, então, visualizar a evolução, ao longo de um determinado período de tempo, de quatro diferentes variáveis que se referem a como as manchetes tratam das personagens pesquisadas: neutras, ambivalentes, favoráveis e contrárias. Segundo o gráfico gerado pela combinação entre a palavra-chave "Lula", o telejornal "Jornal Nacional" e o período "janeiro-2015 a abril-2020", dois grandes picos na variável "contrárias" aparecem: um no começo de 2016, e outro em meados de 2018. Em números, a ferramenta indica que em março de 2016 cerca de 87 matérias contrárias ao ex-presidente Lula foram exibidas no Jornal Nacional, e em abril de 2018, cerca de 53 - picos que são percebidos se postos em comparação com os outros meses, em que a quantidade de matérias contrárias contendo o nome do ex-presidente Lula variou entre o mínimo de 1 e o máximo de 33. Os grandes eventos que acompanham esses picos são o processo de impeachment da então presidenta Dilma Rousseff, em 2016, e a prisão do ex-presidente Lula, em 2018. Uma evolução parecida é observada se o termo "Lula" for trocado por "PT".

Poucos meses depois de o governo Jair Bolsonaro, eleito em 2018, tomar posse, o jornal The Intercept Brasil publicou uma detalhada matéria $^{13}$ revelando e demonstrando, com documentos vazados, uma estranha relação de proximidade entre o juiz Sérgio Moro, responsável pelos julgamentos relacionados à operação Lava-Jato, o procurador

${ }^{13}$ https://theintercept.com/2 020/01/20/linha-do-tempovaza-jato/.

Deltan Dallagnol e veículos de imprensa com linha editorial de direita, como o site $O$ Antagonista. Além disso, as conversas vazadas demonstraram também uma preocupação dos dois juristas com a repercussão midiática e política de cada uma de suas ações.

Essa é a construção narrativa que imputou no petismo a figura do inimigo. Lula, Dilma e o Partido dos Trabalhadores passaram a representar a própria noção abstrata de corrupção. A fabricação de heróis, nesse cenário, é a fabricação de antipetistas, e o herói é qualquer personagem que sirva ao combate contra o petismo - que, por sua vez, tem também seus representantes simbólicos.

O grande passo dado por essa lógica de estetização da política, isto é, da estética para a política efetiva, já foi descrito 
anteriormente, tanto em Walter Benjamin quanto em Slavoj Žižek: a violência sistemática - que, no estágio mais desenvolvido, se manifesta como guerra, a violência de um Estado sobre outro (ou de uma cultura sobre outra). O fundamento dessa concretização política no entanto se encontra antes, no campo da estética: é justamente por encarnar, de forma simbólica dentro da narrativa hegemônica, abstrações como "corrupção", que o inimigo mobiliza as massas unificando em si mesmo os problemas sociais e econômicos, e é justamente por perceber esse inimigo assim que as massas se mobilizam em uma luta redentora para corrigir a corrupção da sua realidade e retornar ao ponto anterior à chegada desse inimigo.

Desse ponto de vista, não é nada surpreendente que o resultado de uma narrativa estetizante da política, que desde seu início atribuiu o claro papel de corruptor da realidade a um partido e seus partidários, seja a eleição com amplo apoio das massas de um projeto político heróico que promete, também desde o início, a eliminação concreta desse corruptor. É justamente esta a incessante vitória que Benjamin descreve nas teses "Sobre o conceito de história". Se cabe aos vencidos a construção de uma historiografia que possibilite o combate à narrativa hegemônica e forneça a eles uma ferramenta de ação política, cabe aos vencedores a continuidade da difusão de sua própria narrativa histórica hegemônica para a manutenção da realidade concreta em que são vencedores. É por meio deste tipo de historiografia que as classes dominantes efetivamente dominam, e a reprodutibilidade dessa historiografia representa sua capacidade de difusão; a estetização da política permite às massas a expressão, e é exatamente este o conteúdo dessa expressão: a reprodução da narrativa histórica burguesa.

O exemplo prático mais didático da confusão entre expressão e concretização, característica da estetização da política, é descrito por Santos (2018: 136):

Homem da velha política, Bolsonaro vendeu-se como o novo. O segredo pode ter sido a forma, não o conteúdo: o ex-capitão maneja a linguagem da brutalidade, que um povo brutalizado conhece e entende. De um modo perverso, ele fala com o povo, como Lula. (...) A constatação que se impõe é que a candidatura de Bolsonaro perverteu a rebeldia. (...) Trata-se de uma dupla 
perversão: porque vendeu o conservadorismo como mudança, mas também porque foi uma candidatura identificada com a disciplina e a ordem, invertendo o sentido comum da rebeldia, que é a insubordinação e a ruptura da ordem.

O próprio autor citado afirma que "nesse sentido, há certa afinidade com o fascismo", entretanto para além das discussões terminológicas sobre a classificação ou não de Jair Bolsonaro e seu projeto dentro da categoria do fascismo ou do neofascismo, é evidente que o triunfo desse projeto só foi possível, pelo menos parcialmente, graças à lógica estetizante segundo a qual opera a política brasileira, notória principalmente na sua cobertura pelos meios de comunicação de massa; isso, para Benjamin, é aspecto fundamental da estética fascista. Há ainda a observação da distância entre a expressão e a concretização nesse caso específico do bolsonarismo: a agenda econômica de Bolsonaro, elaborada por Paulo Guedes - um neoliberal que trabalhou para o regime de Pinochet no Chile - a convite do então candidato, não podia estar mais longe do suporte popular, não contando com a adesão nem da própria base bolsonarista (Santos 2018: 141).

Também não é de se ignorar o preocupante conjunto de elementos discursivos na campanha de Jair Bolsonaro, desde o slogan "Brasil acima de tudo" (e sua assustadora semelhança com o conhecido slogan do Partido Nazista na Alemanha dos anos 30, "Deutzschland über Alles" - em português, "Alemanha acima de tudo"), até a decisiva utilização de redes de difusão massiva de notícias falsas, geralmente envolvendo um projeto conspiratório das organizações de esquerda para corromper crianças brasileiras. ${ }^{14}$

E embora possa se sobrepor a essas semelhanças o frequente argumento de que o projeto bolsonarista, diferente do hitlerista, não se apoia em uma concepção semelhante à do "arianismo" alemão e, portanto, a perseguição que pode resultar dele não é necessariamente essencialista a respeito de alguma etnia específica, como o antissemitismo nazista (que enxergava no judeu a raíz dos problemas econômicos e sociais da Alemanha), é preciso lembrar que, como já visto anteriormente, Benjamin alerta para outra chave de leitura

14 conspiração divulgada pela campanha de Bolsonaro em 2018 é a invenção de que o governo do Partido dos Trabalhadores

distribuía, nas creches do país, mamadeiras cujos bicos possuíam um pênis na ponta. Muitos jornais, na época, precisaram escrever matérias desmentindo a acusação na tentativa de conter os efeitos que pudesse ter nas eleições, como é o caso dessa:

https://politica.estadao. com.br/blogs/estadaoverifica/mamadeiraseroticas-nao-foramdistribuidas-emcreches-pelo-pt/. 
importante, a de que a maneira como a percepção humana se organiza e o meio em que ocorre são historicamente determinados. Isso atribui à estetização da política uma movimentação material e dialética através da história. Ou seja, a maneira como a sociedade capitalista se desenvolve (que determina, entre outras coisas, também o desenvolvimento das técnicas de reprodução e, portanto, o grau de reprodutibilidade da obra de arte), sua realidade concreta e material, é o que dialeticamente determina a relação estética entre a arte e o público - a forma dessa arte e (o que são, também dialeticamente, ao mesmo tempo) seus meios de reprodução, como cinema e televisão, são justamente resultados do desenvolvimento das técnicas de reprodução, e o público, regularmente exposto a essas formas e meios, têm por estes sua percepção dialeticamente moldada.

Dessa forma, embora no caso do Brasil a mobilização das massas pelo projeto bolsonarista seja alimentada pela imagem do inimigo representada no petismo e não em um grupo étnico específico (como os judeus, na Alemanha hitlerista), a própria lógica dessa mobilização de massas enraizada na estetização da política "à brasileira", na percepção das massas dá conta de ajustar os parâmetros da realidade quando necessário. Um exemplo concreto disso é o comportamento, por exemplo, que a extrema-direita bolsonarista manifesta, nas ruas e nas redes, ${ }^{15}$ ao se deparar com a concretude da realidade brasileira. Nas eleições de 2018 e em várias eleições anteriores, a região do nordeste foi o suporte eleitoral do Partido dos Trabalhadores, com mais votos para a legenda no primeiro e no segundo turnos, e com mais governadores petistas eleitos. Também durante as eleições de 2018, poucos dias antes do segundo turno, uma pesquisa realizada pelo Instituto Datafolha ${ }^{16}$ mostrava que, se divididos por religiões, os eleitores adeptos das religiões de matriz africana declaravam muito mais votos para o Partido dos Trabalhadores do que para Jair Bolsonaro. Imediatamente, o inimigo que em uma conceituação abstrata é o petista, se manifesta concretamente como o nordestino ou o negro, como demonstram sombrios episódios de discriminação e até assassinato por "motivos políticos" ocorridos no calor das eleições de 2018.
15 A exemplo disso, vários episódios podem ser lembrados, entre eles os constantes ataques aos nordestinos nas redes sociais, 0 assassinato de Moa do Katendê, ou até mesmo a importação direta do antissemitismo que em teoria não tem motivos em sua história recente para se manifestar no Brasil. Todos esses casos podem ser conferidos, respectivamente, em: https://oglobo.globo.co m/brasil/nordestinossao-atacados-nasredes-sociais-aposresultado-do-primeiroturno-23138271,

https://g1.globo.com/ba /bahia/noticia/2018/10/1 7/investigacao-policialconclui-que-morte-demoa-do-katende-foimotivada-por-brigapolitica-inquerito-foienviado-ao-mp.ghtml e https://ponte.org/comavanco-da-extremadireita-antissemitismose-recicla-e-volta-aatacar/.

16 Disponivel em: https://g1.globo.com/pol itica/eleicoes/2018/eleica o-em-

numeros/noticia/2018/10 /26/datafolha-de-25-deoutubro-parapresidente-por-sexoidade-escolaridaderenda-regiao-religiao-eorientacao-sexual.ghtml. 
A tarefa de "escovar a história a contrapelo", atribuída por Walter Benjamin a uma historiografia revolucionária, é a tarefa de construir um espaço de luta contra-hegemônica na maneira como a narrativa histórica é escrita. É uma tarefa já prenunciada pelo duplo caráter do documento histórico: cultura e, ao mesmo tempo, barbárie. Ela encontra seu par na tarefa de "politizar a arte", que embora apareça inconclusa no ensaio de Benjamin, aponta um plano de ação: construir um espaço de luta contra-hegemônica na maneira como a própria percepção humana se organiza. Nesse espaço se faz possível a formação de uma consciência de classe que desnude a barbárie e force sua interrupção, qualquer que seja a forma historicamente determinada com que ela se manifeste.

\section{REFERÊNCIAS BIBLIOGRÁFICAS}

BENJAMIN, W. A obra de arte na era de sua reprodutibilidade técnica. Trad. G.V. Silva. Porto Alegre: L\&PM, 2018 [1980].

W. "Tese VII". In: LÖWY, M. Aviso de incêndio: uma leitura das teses sobre o conceito de história. Trad. W.N.C. Brant. Trad. das teses: J.M. Gagnebin. São Paulo: Boitempo, 2005 [1940].

BUCK-MORSS, S. A tela do cinema como prótese de percepção. Trad. A.L. Andrade. Florianópolis: Cultura e Barbárie, 2009 [1994].

HOFFMANN, A.G., MARTINO, L.M.S. Os nomes da operação Lava-Jato: aproximações e apropriações do entretenimento no campo político. Revista Comunicação Midiática, v. 12, n. 3, p. 145-157, 2017.

JAPIASSÚ, H., MARCONDES, D. Dicionário básico de filosofia. Rio de Janeiro: Jorge Zahar Ed., 2001.

LUKÁCS, G. Marxismo e teoria da literatura. Trad. C.N. Coutinho. São Paulo: Expressão Popular, 2010 [1968].

MARX, K. A ideologia alemã. Trad. R. Enderle, N. Schneider, L.C. Martorano. São Paulo: Boitempo, 2007 [1932].

K. O 18 de brumário de Luís Bonaparte. Trad. N. Schneider. São Paulo: Boitempo, 2011 [1852]. 
PAXTON, R. Anatomia do fascismo. Trad. Patrícia Zimbres, Paula Zimbres. São Paulo: Paz e Terra, 2007 [2004].

PLATÃO. A república. Trad. M.H.R. Pereira. Lisboa: Fundação Calouste Gulbenkian, 1996 [376 a.c].

SANTOS, F.L.B. Uma história da onda progressista sul-americana: 19982016. São Paulo: Editora Elefante, 2018.

THALHEIMER, A. Sobre o fascismo. Trad. O. Miranda, S.A. Paiva. Salvador: Centro de Estudos Victor Meyer, 2009 [1930].

VASCONCELLOS, F. A construção de imagens do Jornal Nacional durante o escândalo do Mensalão. Revista Compolítica, v. 1, n. 4, p. 81118, 2014.

ŽIŽEK, S. Violência. Trad. M.S. Pereira. São Paulo: Boitempo, 2014 [2007]. 